\title{
A continuous conversion technology from top coal caving into multi-slice mining for thick bifurcated coal seams
}

\section{Xuejie Deng ( $\sim$ dengxi1989@gmail.com )}

China University of Mining and Technology - Beijing

Hao Liu

China University of Mining and Technology - Beijing

Jianye Feng

China University of Mining and Technology - Beijing

Yu Li

China University of Mining and Technology - Beijing

\section{Benjamin de Wit}

University of British Columbia

\section{Research Article}

Keywords: Thick bifurcated coal seam, continuous conversion mining technology, top coal caving, multislice mining

Posted Date: March 11th, 2021

DOI: https://doi.org/10.21203/rs.3.rs-276701/v1

License: (c) (i) This work is licensed under a Creative Commons Attribution 4.0 International License. Read Full License

Version of Record: A version of this preprint was published at Geotechnical and Geological Engineering on June 22nd, 2021. See the published version at https://doi.org/10.1007/s10706-021-01898-6. 


\section{Abstract}

This paper presents a mining technology that enables the continuous conversion from top coal caving (TCC) to multi-slice mining (MSM). The technology helps operations overcome challenges with mining thick bifurcated coal seams, particularly the challenge of rock-parting seams affecting the caving of TCC mining methods. Findings show that the relationship between the rock-parting thickness and the caveability of top coal can be divided into 3 phases, including a complete caving phase, a transition phase, and a stable phase. This continuous conversion technology was applied in the Zhongwei Coal Mine in which TCC was used to extract the initial $260 \mathrm{~m}$ of the study area where the rock-parting seam was relatively thin before a transition to MSM was made due to the rock-parting seam becoming significantly thicker. The continuous conversion to MSM involved the working face advancing upward at an angle of 10 degrees until the rock-parting seam could serve as the immediate floor for the upper slice of the coal seam. The rock-parting seam floor also acted as the immediate roof for the working face of the subsequently mined lower slice. The application of this continuous conversion mining technology obtained good application results.

\section{Introduction}

BP Statistical Review of World Energy (2019) (Amoco 2019)shows that the demonstrated coal reserves of the world are estimated at 1.055 trillion tonnes, and approximately $30 \%$ of the total coal reserves are found as thick coal seams with a thickness over $3.5 \mathrm{~m}$ (Ghose 1984). There is no unified definition for thick coal seams all over the world. Generally, when a coal seam cannot be exploited conveniently in a single pass using the currently available equipment, it could be defined as a thick seam. Since currently available mining methods and equipment could make it feasible to exploit a wide range of seam thicknesses, the definition of the thick coal seam is various in different countries, as shown in Table 1.

\section{Table 1 Minimum thickness of coal seam to be called thick in different countries}

\begin{tabular}{|lll|}
\hline Country & Minimum thickness to be a thick seam $(\mathrm{m})$ & Total workable reserve $(\mathrm{Mt})$ \\
\hline Australia & 4.0 & 18128 \\
\hline China & 3.5 & 98883 \\
\hline Canada & 4.0 & 8708 \\
\hline India & 4.8 & 35345 \\
\hline Turkey & 3.5 & 6056 \\
\hline USA & 3.0 & 113230 \\
\hline
\end{tabular}

Table 1 shows that the minimum thickness to be a thick seam is in the range of $3.0 \mathrm{~m}$ to $4.8 \mathrm{~m}$, the coal seam with a thickness over $3.5 \mathrm{~m}$ is considered as a thick coal seam in China. Based on the most 
advanced longwall mining technology, the coal seam with a thickness between $3.5 \mathrm{~m}$ to $7 \mathrm{~m}$ is defined as the thick coal seam, and the coal seam above $7 \mathrm{~m}$ as the extra-thick coal seam in this paper. Mineable coal reserves in thick and extra-thick seams account for $44 \%$ of the total reserves in China, and over $60 \%$ in India (Rakesh et al. 2015). Top coal caving (TCC) is one of the main technologies used to efficiently mine thick and extra-thick coal seams, the method is widely used in China, Turkey, Russia, Australia, and India (Cai 2004; Jia-chen 2005; Khanal et al. 2014). To implement the TCC mining method, the TCC panel is established along the floor of the thick coal seam and a continuous shearer is used to extract the portion of the coal seam that is located beneath the hydraulic supports. Once the bottom portion of the thick coal seam is extracted the caving process begins by advancing the hydraulic supports to allow the in-situ coal located above to cave down under the force of gravity. This caved coal is transported by the armored face conveyor installed at the rear of the support. The technical principles of TCC (Habib and Alehossein 2010; Le 2018; Le et al. 2017) are shown in Fig. 1.

In cases when the thick coal seam is bifurcated and becomes two or several slices due to the influence of the thick rock-parting seam, it is difficult to recover the entire coal seam using only the TCC method. For the bifurcated coal seam, the common practice is to stop mining in the area where the thick rock-parting seam occurs and to begin a new TCC panel in an area without thick rock-partings. This solution results in a significant amount of coal being left underground, lower recovery rates, higher production costs, and discontinuous operations. Although multi-seam mining has been applied in many countries, such as Poland, India, and China, the efficient multi-seam mining method specialized for the bifurcated coal seam has not been reported (Cheng et al. 2020; Ghosh et al. 2020; Szott et al. 2018).

In order to find a solution to these problems, this paper presents the continuous conversion mining technology that allows an operation to transition from TCC into multi-slice mining (MSM) when recovering thick bifurcated coal seams. The implementation and analysis of the continuous conversion mining technology in the Zhongwei Coal Mine is used as an example of the method being applied in the field. The influence of the rock-parting seam on the top coal caving ratio is also studied in this research. This continuous conversion mining technology can provide a viable solution for underground coal mines to continuously extract bifurcated coal seams and enrich the mining methods for thick coal seams with complex conditions (Kushwaha et al. 2016; Zhang et al. 2019).

\section{Geological Conditions Of The Coal Mine}

\subsection{Location}

The Zhongwei coal mine is located $40 \mathrm{~km}$ northwest of Baicheng city, Aksu region, Xinjiang, China. The mine field is located at the southern foot of Tianshan Mountain with the terrain trending from northeast to southwest. The location of the mine is shown in Fig. 2.

\subsection{Geological conditions of the bifurcated coal seam}


The surface area of the mine field is $13.48 \mathrm{~km} 2$, and the production capacity of the mine is $0.9 \mathrm{Mt} / \mathrm{a}$. The strike of the coal seam is north by East, with a tendency of 135 degrees to 165 degrees and a dip angle of 28 degrees to 32 degrees, an average of 30 degrees. The stratigraphic columns and the layout of the Zhongwei coal mine are shown in Fig. 3.

As shown in Figure $3(\mathrm{~b})$, the ground elevation of drill hole $10-1$ is $+2730 \mathrm{~m}$, and the elevation of the coal seam floor is $+2322 \mathrm{~m}$. Drill hole 10-1 shows that the immediate roof of the coal seam IV13 in the study area is composed of sandy mudstone and mudstone, with an average thickness of $7.93 \mathrm{~m}$. The main roof is off-white medium sandstone with an average thickness of $21.6 \mathrm{~m}$. The immediate floor is primarily dark gray siltstone with an average thickness of $7.07 \mathrm{~m}$ and the main floor is composed of dark gray medium sandstone, including quartz, with an average thickness of $2.63 \mathrm{~m}$. The average thickness of coal seam IV13 is $5.5 \mathrm{~m}$. The original plan was to apply TCC in this area with a cutting height of $2.4 \mathrm{~m}$, a top coal caving height of $3.1 \mathrm{~m}$, and a resulting cutting to caving ratio of 1:1.3. However, as shown in drill hole 10-2, a thick rock-parting seam appears in the coal seam, situated along strike from the setup room and extending $260 \mathrm{~m}$. The ground elevation of drill hole 10-2 is $+2730 \mathrm{~m}$, and the floor elevation of the lower slice of the coal seam is $+2352 \mathrm{~m}$. The average thickness of this rock-parting seam over the first $260 \mathrm{~m}$ from the setup room is relatively small at about $0.3 \mathrm{~m}$, but beyond $260 \mathrm{~m}$ this rock-parting seam is much thicker and ranges from $1.5 \mathrm{~m}$ to $2.3 \mathrm{~m}$. This issue results in a bifurcated phenomenon of the coal seam. Coal seam IV13 becomes two slices, where the average thicknesses of the upper slice and lower slice are $2.9 \mathrm{~m}$ and $2.07 \mathrm{~m}$ respectively. This bifurcated section of the coal seam makes it difficult to implement caving using TCC technology because the rock-parting seam has a relatively large thickness and is composed of strong materials.

\section{Mining Methods}

\subsection{The influence of the rock-parting seam on the top coal caving ratio}

In order to study the influence of the rock-parting seam on top coal caveability, the rock-parting seam is simplified as a cantilever beam and the weight of the overburden material is simplified as a uniform load being applied to this beam. Using mechanical analysis, the relationship between the thickness of the rock-parting seam and the caveability of the top coal can be obtained, as shown in Fig.4.

Fig. 4 shows that when the strength of the rock-parting seam is constant, the relationship between the thickness of the rock-parting seam and the caveability of the top coal can be divided into 3 phases. First, the complete caving phase. When the thickness of the rock-parting seam is less than the transition thickness $\left(h_{t}\right)$, the cantilever beam structure breaks under the force of gravity when the working face and the hydraulic roof supports advance. In this phase, the rock-parting seam is thin and does not inhibit the complete caving of the top coal. The second phase is the transition phase. When the rock-parting seam thickness is greater than the transition thickness $\left(h_{t}\right)$ but less than the critical thickness $\left(h_{l}\right)$ the rockparting blocks are too large and only partial caving occurs, which results in arch structures being formed in the top coal. The top coal only partially caves because of the increased thickness of the rock-parting 
seam and a resulting decrease in caveability. The third phase is the stable phase. When the thickness of the rock-parting seam is greater than the critical thickness $\left(h_{l}\right)$ the cantilever beam structure cannot be broken and does not cave regularly during the mining process. The rock-parting seam forms an isolation zone which can block the top coal from caving, so the top coal becomes stable and remains in-situ. The MSM method should be applied in this phase.

Based on the conditions of the Zhongwei coal mine the calculation results show that the critical thickness $\left(h_{l}\right)$ is $1.359 \mathrm{~m}$. The rock-parting seam is $0.3 \mathrm{~m}$ thick over the first $260 \mathrm{~m}$ of the panel, which is less than $1.359 \mathrm{~m}$, so the TCC method is practical in this area. Beyond $260 \mathrm{~m}$ from the setup room, the thickness of the rock-parting seam is greater than $1.359 \mathrm{~m}$, which means that the TCC mining method is no longer practical and the mining method is continuously converted from TCC to MSM. In the MSM stage, the upper coal seam is initially mined, followed by the lower coal seam.

\subsection{The continuous conversion mining technology from TCC into MSM}

(1) The continuous conversion process from TCC into MSM

(a) TCC phase

At the Zhongwei coal mine, the thickness of the rock-parting seam is only $0.3 \mathrm{~m}$ over the first $260 \mathrm{~m}$ of the Panel 12031 along the strike direction from the setup room. This thickness is less than the transition thickness which allows for TCC technology to be applied effectively and the result is complete caving of both the relatively thin rock-parting seam and the top coal. Cutting is used to recover $2.4 \mathrm{~m}$ of the height of the coal seam and top coal caving is used to recover an additional $3.1 \mathrm{~m}$ of the height of the coal seam, creating a cutting to caving ratio of approximately 1:1.3.

(b) Transition phase

After the TCC working face advances $260 \mathrm{~m}$ from the setup room, the thickness of the rock-parting seam becomes greater than the critical thickness. This increased thickness of the rock-parting seam is accommodated by transitioning from the TCC method to the MSM method. This transition begins with the working face advancing upward at an angle of 10 degrees until the floor of the working face rises above the rock-rock-parting seam. Once the working face is above the rock-parting seam the mining direction is changed to the strike of the upper slice of coal seam IV13. Also, the mining method changes from TCC to MSM.

(c) MSM phase

In the MSM phase the two coal seams, including the upper slice and lower slice of coal seam IV13, are mined. To mining the upper slice, the MSM working face moves with the rock-parting seam as the immediate floor, and the average mining height is $2.9 \mathrm{~m}$. After finishing the extraction of the upper slice, panel 12032 (shown in Fig. 3) is established along the floor of the lower slice with an average mining height of $2.07 \mathrm{~m}$. The rock-parting seam acts as the immediate roof of this MSM working face. 
The continuous conversion process from TCC into MSM for the thick bifurcated coal seam is shown in Fig. 5.

(2) The setup room in the lower coal seam after bifurcation occurs

In the MSM phase, after the gob of the Panel 12031 has been compacted, Panel 12032 is established and designed along the floor of the lower slice with the rock-parting seam acting as the immediate roof. The FLAC3D is used to simulate and analyze the location of the setup room of Panel 12032. The size of the whole model is $475.7 \mathrm{~m} \times 150 \mathrm{~m} \times 100 \mathrm{~m}$. The length of working faces is $160 \mathrm{~m}$, the advancing length is $200 \mathrm{~m}$, and boundary pillars with a width of $50 \mathrm{~m}$ are reserved on both sides of the model to avoid the boundary effect. Considering the calculation accuracy and computing power, the model is divided into 327888 units with 347738 nodes. The mechanical boundary conditions of the model are set as follows: the front, back, left and right boundary are fixed in $\mathrm{X}$ and $\mathrm{Y}$ directions; the bottom boundary is fully constrained; a uniform vertical load of $5 \mathrm{MPa}$ is applied on the top boundary of the model, the load is equivalent to the weight of the overlying strata. The structure of the numerical simulation model is shown in Fig. 6, the key parameters of the strata are listed in Table 2.

\section{Table 2 The key parameters of the strata in the numerical simulation model}

\begin{tabular}{|lllllll|}
\hline Lithology & $\begin{array}{l}\text { Bulk } \\
\text { modulus } \\
(\mathrm{GPa})\end{array}$ & $\begin{array}{l}\text { Shear } \\
\text { modulus } \\
(\mathrm{GPa})\end{array}$ & $\begin{array}{l}\text { Density } \\
\left(10^{3} / \mathrm{kg} \cdot \mathrm{m}^{-3}\right)\end{array}$ & $\begin{array}{l}\text { Tensile } \\
\text { strength } \\
(\mathrm{MPa})\end{array}$ & $\begin{array}{l}\text { Cohesion } \\
(\mathrm{MPa})\end{array}$ & $\begin{array}{l}\text { Internal } \\
\text { friction } \\
\text { angle } \\
\left({ }^{\circ}\right)\end{array}$ \\
\hline Gritstone 1 & 23.3 & 13.2 & 2.6 & 3.1 & 8.3 & 32 \\
\hline $\begin{array}{l}\text { Fine } \\
\text { sandstone }\end{array}$ & 18.5 & 12.6 & 2.6 & 2.5 & 3.1 & 25 \\
\hline $\begin{array}{l}\text { Quartz } \\
\text { sandstone }\end{array}$ & 17.8 & 12.2 & 2.6 & 1.5 & 1.58 & 30 \\
\hline Siltstone 1 & 20.5 & 1.2 & 2.6 & 1.1 & 1.26 & 26 \\
\hline $\begin{array}{l}\text { Coal seam } \\
\square_{13}\end{array}$ & 8.6 & 0.9 & 1.38 & 1.8 & 1.96 & 26 \\
\hline $\begin{array}{l}\text { Upper coal } \\
\text { seam } \mathbb{\Xi}_{13}\end{array}$ & 8.6 & 0.9 & 1.38 & 1.8 & 1.96 & 26 \\
\hline Mudstone & 8.3 & 1.6 & 2.7 & 2.1 & 2.26 & 26 \\
\hline $\begin{array}{l}\text { Lower coal } \\
\text { seam } \mathbb{B}_{13}\end{array}$ & 8.6 & 0.9 & 1.38 & 1.8 & 1.96 & 26 \\
\hline Siltstone 2 & 20.5 & 2.9 & 2.7 & 1.6 & 1.3 & 33 \\
\hline Gritstone 2 & 17.8 & 4.6 & 2.7 & 3 & 4 & 33 \\
\hline
\end{tabular}


During the simulation, the gate roads of 12031 in the MSM phase and TCC phase are firstly excavated. Then, the working face 12031 is advanced gradually with the advancing distance of $50 \mathrm{~m}, 100 \mathrm{~m}, 150 \mathrm{~m}$, $200 \mathrm{~m}$, and $250 \mathrm{~m}$. The setup room and gate roads of Panel 12032 are opened after the Panel 12031 is mined out, the barrier pillar is set at different width of $10 \mathrm{~m}, 20 \mathrm{~m}$, and $30 \mathrm{~m}$. Finally, Panel 12032 is mined out with different panel layouts. The simulation results are shown in Fig. 7.

Fig. 7 shows that when the barrier coal pillar between the setup room of the Panel 12032 and the TCC area of the Panel 12031 is $10 \mathrm{~m}$, the pillar undergoes plastic failure and eventually causes instability. The elastic core region of the coal pillar increases gradually when the width of the coal pillar increases. When the coal pillar reaches $30 \mathrm{~m}$ in width, the stable elastic core region reaches $20 \mathrm{~m}$ which indicates the pillar has good stability. Therefore, the reasonable width of the coal pillar can be designed to $30 \mathrm{~m}$.

The gate roads of the Panel 12031 including the TCC phase and MSM phase are excavated firstly, then the Panel 12031 is continuously mined with the continuous conversion mining technology from TCC into MSM. After the Panel 12031 is mined out completely, the gate roads of Panel 12032 are excavated along the floor of the coal seam, and it is $8 \mathrm{~m}$ staggered inward comparing to the Panel 12031, as shown in Fig. 8. Finally, the setup room of Panel 12032 is excavated with a barrier pillar of $30 \mathrm{~m}$, as shown in Fig. 7 .

\section{Application Effects}

\subsection{Social benefits}

This new continuous conversion mining technology from TCC to MSM provides a new technical scheme and enriches the mining methods for thick bifurcated coal seams. Moreover, it enriches the ground control theory related to TCC and MSM of ultra-close coal seams. The successful application of this technology can provide technical references for mines under similar conditions.

\subsection{Economic benefits}

Through the application of this technology for thick bifurcated coal seams, mining technology and the roadway layout are optimized for the studied area. The total net economic benefit is about 233.9 million CNY. The composition of the economic benefits is shown in Table 3.

\section{Table 3 The composition of economic benefits}




\begin{tabular}{|llllll|}
\hline Categories & Units & $\begin{array}{l}\text { 12031 Panel } \\
(\text { TCC })\end{array}$ & $\begin{array}{l}\text { 12031 Panel } \\
(\text { MSM })\end{array}$ & $\begin{array}{l}\text { 12032 Panel } \\
(\text { MSM })\end{array}$ & Cumulative \\
\hline Unit costs & $\mathrm{CNY} / \mathrm{t}$ & 190.7 & 246.9 & 211.8 & - \\
\hline Unit prices & $\mathrm{CNY} / \mathrm{t}$ & 380.0 & 480.0 & 390.0 & - \\
\hline Unit profits & $\mathrm{CNY} / \mathrm{t}$ & 189.3 & 233.1 & 178.2 & - \\
\hline $\begin{array}{l}\text { Total } \\
\text { outputs }\end{array}$ & $\times 10^{4} \mathrm{t}$ & 27.7 & 60.5 & 22.7 & 110.9 \\
\hline $\begin{array}{l}\text { Total sales } \\
\text { Million }\end{array}$ & 105.26 & 290.40 & 88.53 & 484.19 \\
\hline $\begin{array}{l}\text { Total } \\
\text { profits }\end{array}$ & $\begin{array}{l}\text { Million } \\
\mathrm{CNY}\end{array}$ & 52.44 & 141.03 & 40.45 & 233.92 \\
\hline
\end{tabular}

\section{Conclusion}

The main conclusions are listed as follows:

(1) The influence of the rock-parting seam on the caveability of the top coal is analyzed and the results indicate that the caveability of the top coal decreases with an increase in the thickness and the strength of the rock-parting seam. The concepts of transition thickness and critical thickness of the rock-parting seam are proposed. The critical thickness of the rock-parting seam in Zhongwei Coal Mine is found to be $1.359 \mathrm{~m}$.

(2) The continuous conversion mining technology from TCC into MSM for the thick bifurcated coal seam is presented and applied in Zhongwei Coal Mine. The TCC technology is used in the area with a relatively thin rock-parting seam and the TCC working face advances until the rock-parting seam thickness equals or exceeds the critical thickness. When the rock-parting seam exceeds the critical thickness the TCC working face advances upward at an angle of 10 degrees to convert into MSM. The MSM working face moves with the rock-parting seam as the immediate floor for the upper slice, and the floor of the rockparting seam acts as the immediate roof for the lower coal slice.

(3) The FLAC3D is used to simulate and analyze the location of the setup room of Panel 12032. A reasonable width for the barrier coal pillar between the setup room of Panel 12032 and the TCC area is determined to be $30 \mathrm{~m}$.

(4) The application of this continuous conversion mining technology not only obtains obvious economic benefits but also provides technical references for mines with similar bifurcated coal seams.

\section{Declarations}

\section{Acknowledgments}


The authors would like to acknowledge the Zhongwei coal mine, Xinjiang, China, for providing the study area and the financial support. Special thanks are given to Dr. Hengfeng Liu and Dr. Peng Huang for their technical assistance during the research.

\section{Funding}

This work was supported by National Key R\&D Program of China [Grant Number 2018YFC0604701], National Natural Science Foundation of China (Youth Program) [Grant Number 51804308], the Yue Qi Young Scholar Project [Grant Number 2020QN03], and the China Postdoctoral Science Foundation [Grant Number 2020T130269, 2020M670689].

\section{Declaration of Competing Interest}

The authors declared that there is no conflict of interest.

\section{References}

Amoco B (2019) BP Statistical Review of World Energy 2019 BP Magazine 2019:42-47

Cai Y (2004) Application of longwall top coal caving to Australian operations. University of New South Wales, Australia

Cheng Z, Ouyang Z, Zou Q, Lu Y, Zhao X, Li M (2020) Characteristics of fracture field in different stress zones during multi-seam mining: Quantification based on theoretical analysis and BBM-DEM accurate simulation method Energy Science \& Engineering 8:1620-1633 doi:https://doi.org/10.1002/ese3.620

Ghose AK (1984) Underground methods of extraction of thick coal seams-a global survey Mining Science and Technology 2:17-32

Ghosh N, Agrawal H, Singh SK, Banerjee G (2020) Optimum Chain Pillar Design at the Deepest MultiSeam Longwall Workings in India Mining, Metallurgy \& Exploration 37:651-664 doi:https://doi.org/10.1007/s42461-019-00138-z

Habib, Alehossein (2010) Stress analysis of longwall top coal caving International Journal of Rock Mechanics and Mining Sciences doi:https://doi.org/10.1016/j.ijrmms.2009.07.004

Jia-chen W (2005) Fully mechanized longwall top coal caving technology in China and discussion on issues of further development [J] Coal science and technology doi:https://doi.org/10.13199/j.cst.2005.01.16.wangjch.005

Khanal M, Adhikary D, Balusu R (2014) Prefeasibility study-Geotechnical studies for introducing longwall top coal caving in Indian mines Journal of Mining Science 50:719-732 doi:https://doi.org/10.1134/S1062739114040139 
Kushwaha A, Bhattacharjee R, Tewari S, Mandal P (2016) Role of geological discontinuities during application of continuous miner technology in underground coal mines Jour Mines, Metals \& Fuels 64:395-405

Le TD (2018) Longwall Top Coal Caving Mechanism and Cavability Assessment. University of New South Wales

Le TD, Mitra R, Oh J, Hebblewhite B (2017) A review of cavability evaluation in longwall top coal caving International Journal of Mining Science and Technology 27:907-915

doi:https://doi.org/10.1016/j.ijmst.2017.06.021

Rakesh K, Kumar SA, Kumar MA, Rajendra S (2015) Underground mining of thick coal seams International Journal of Mining Science and Technology 000:P.885-896

Szott W, Słota-Valim M, Gołąbek A, Sowiżdżał K, Łętkowski P (2018) Numerical studies of improved methane drainage technologies by stimulating coal seams in multi-seam mining layouts International Journal of Rock Mechanics and Mining Sciences 108:157-168

doi:https://doi.org/10.1016/j.ijrmms.2018.06.011

Zhang J, Deng X, Liu H (2019) A continuous conversion technology from top coal caving into multi-slice mining for thick bifurcated coal seams. China Patent CN109915144A,

\section{Figures}




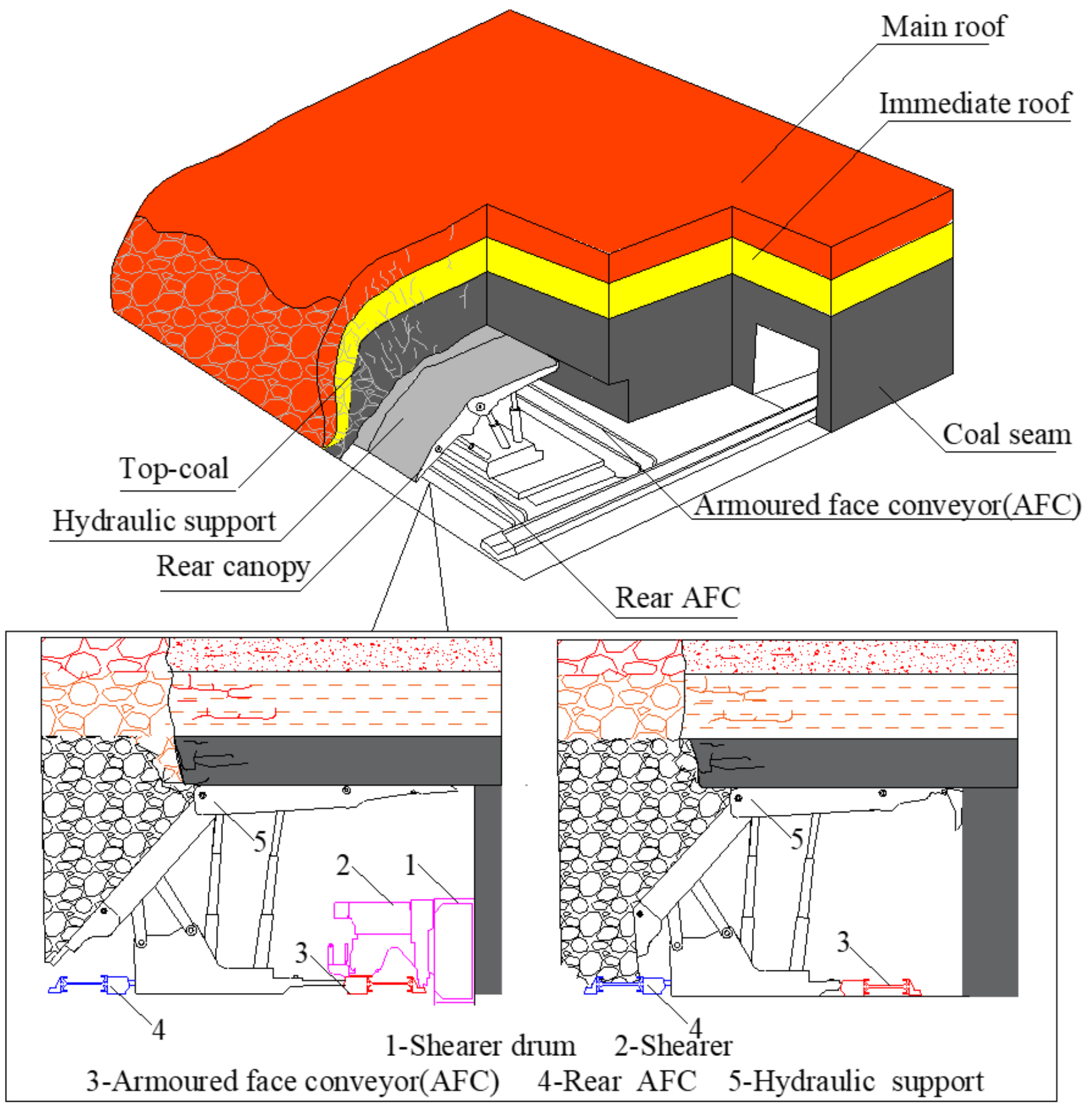

Figure 1

The technical principle of TCC 


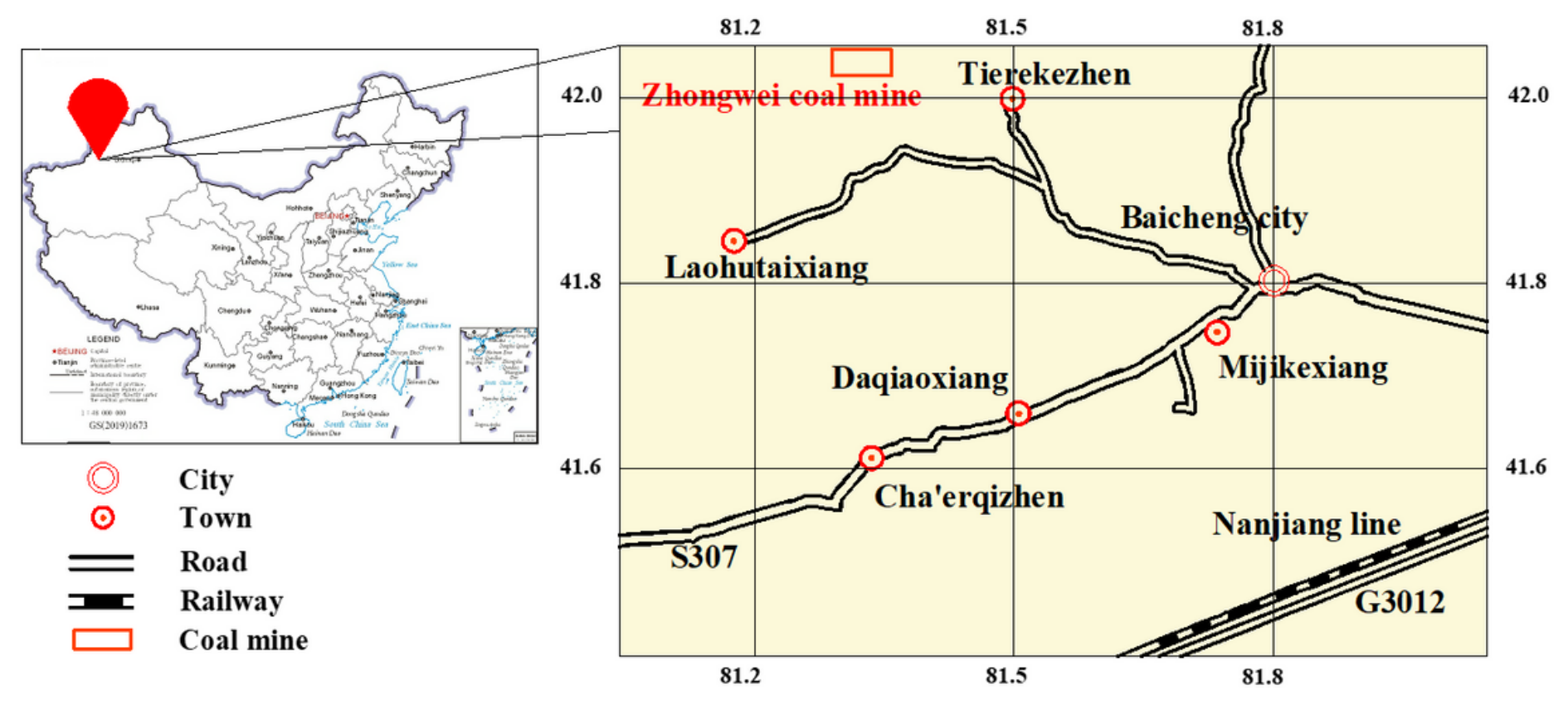

Figure 2

Location of the Zhongwei coal mine. Note: The designations employed and the presentation of the material on this map do not imply the expression of any opinion whatsoever on the part of Research Square concerning the legal status of any country, territory, city or area or of its authorities, or concerning the delimitation of its frontiers or boundaries. This map has been provided by the authors.

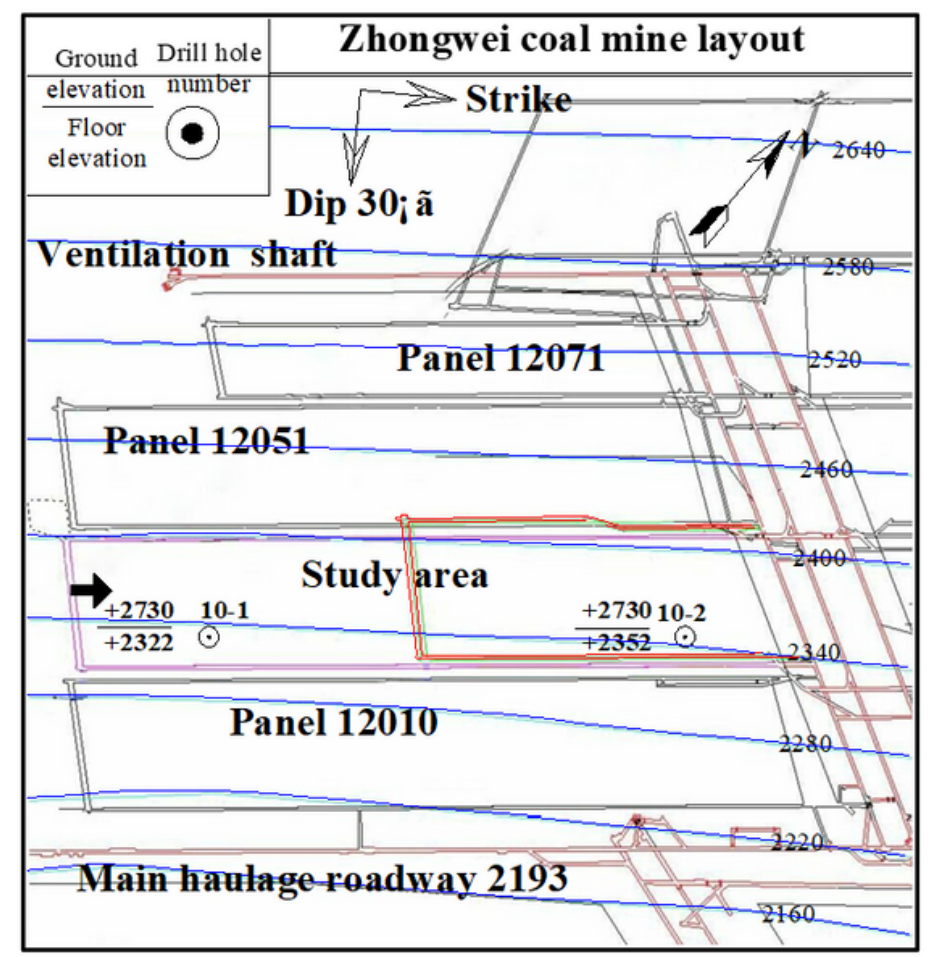

(a) The layout of panels

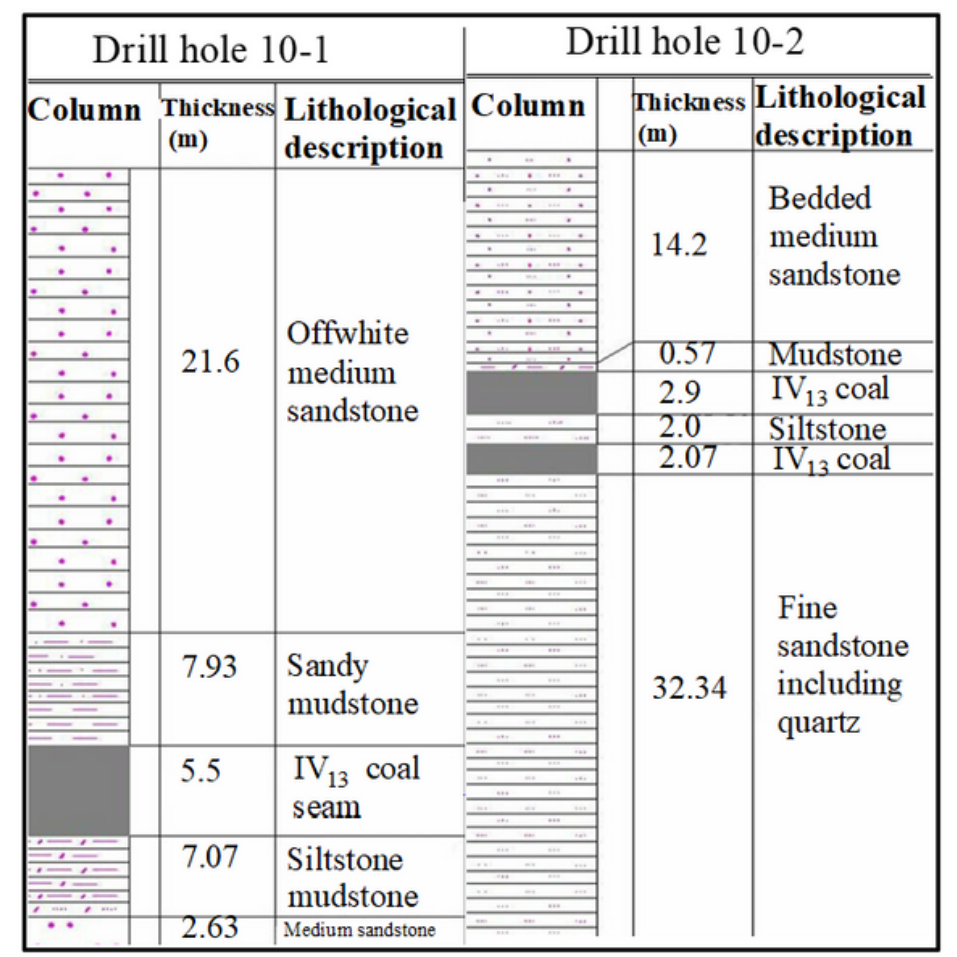

\section{(b) Stratigraphic column}


Figure 3

The layout and stratigraphic column of the Zhongwei coal mine

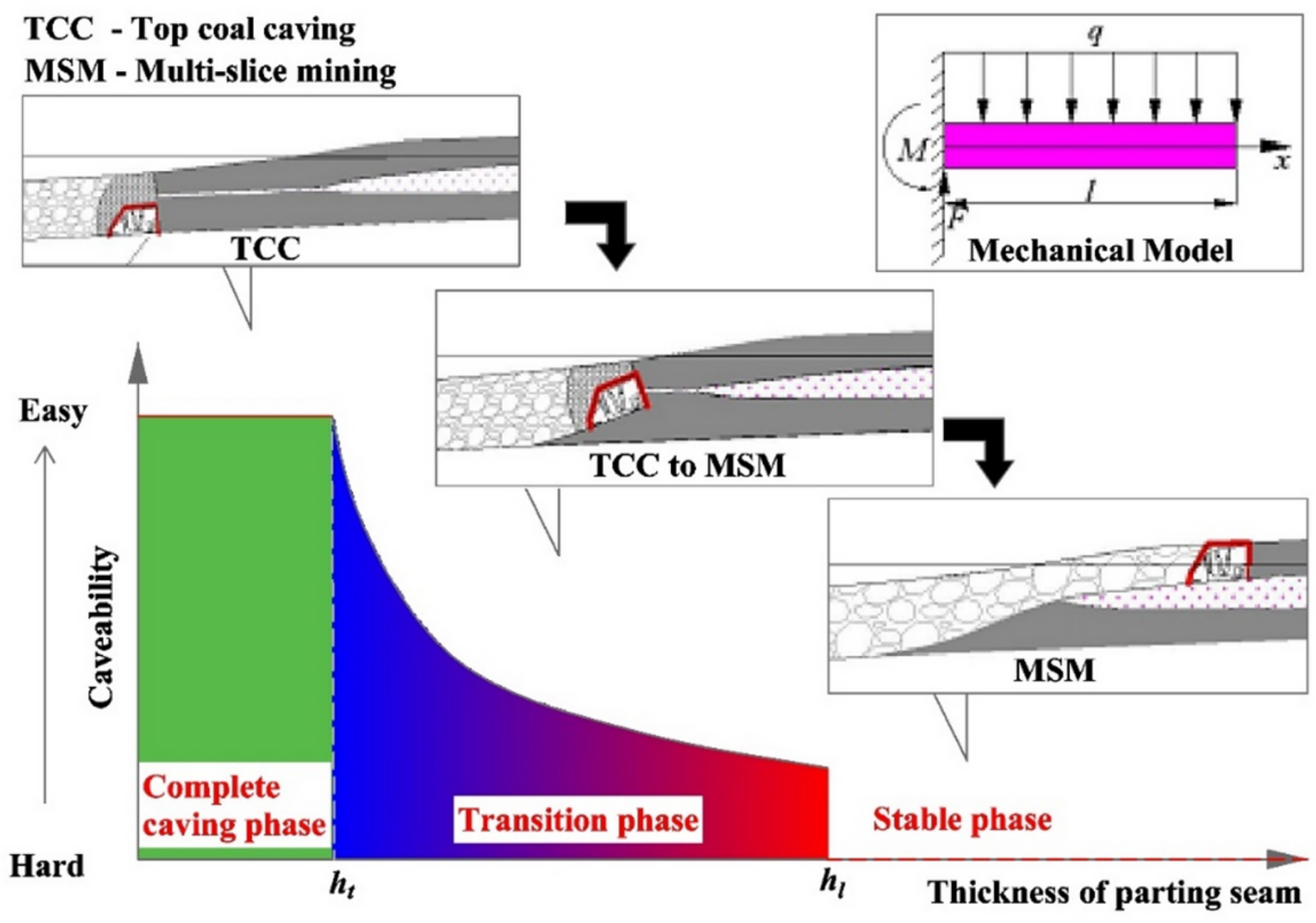

Figure 4

The relationship between the thickness of the rock-parting seam and the caveability of the top coal 


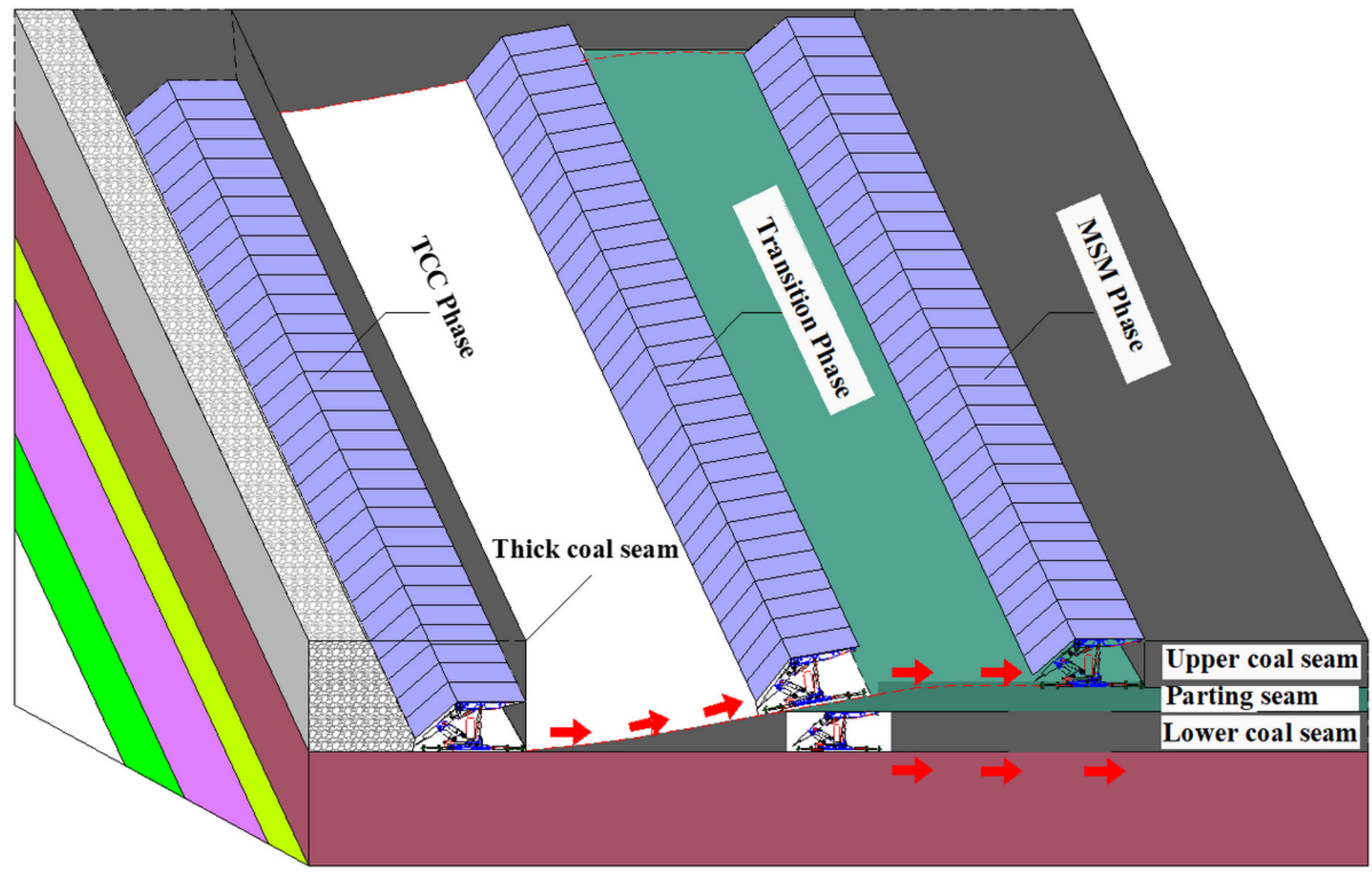

Figure 5

The continuous conversion process from TCC into MSM 


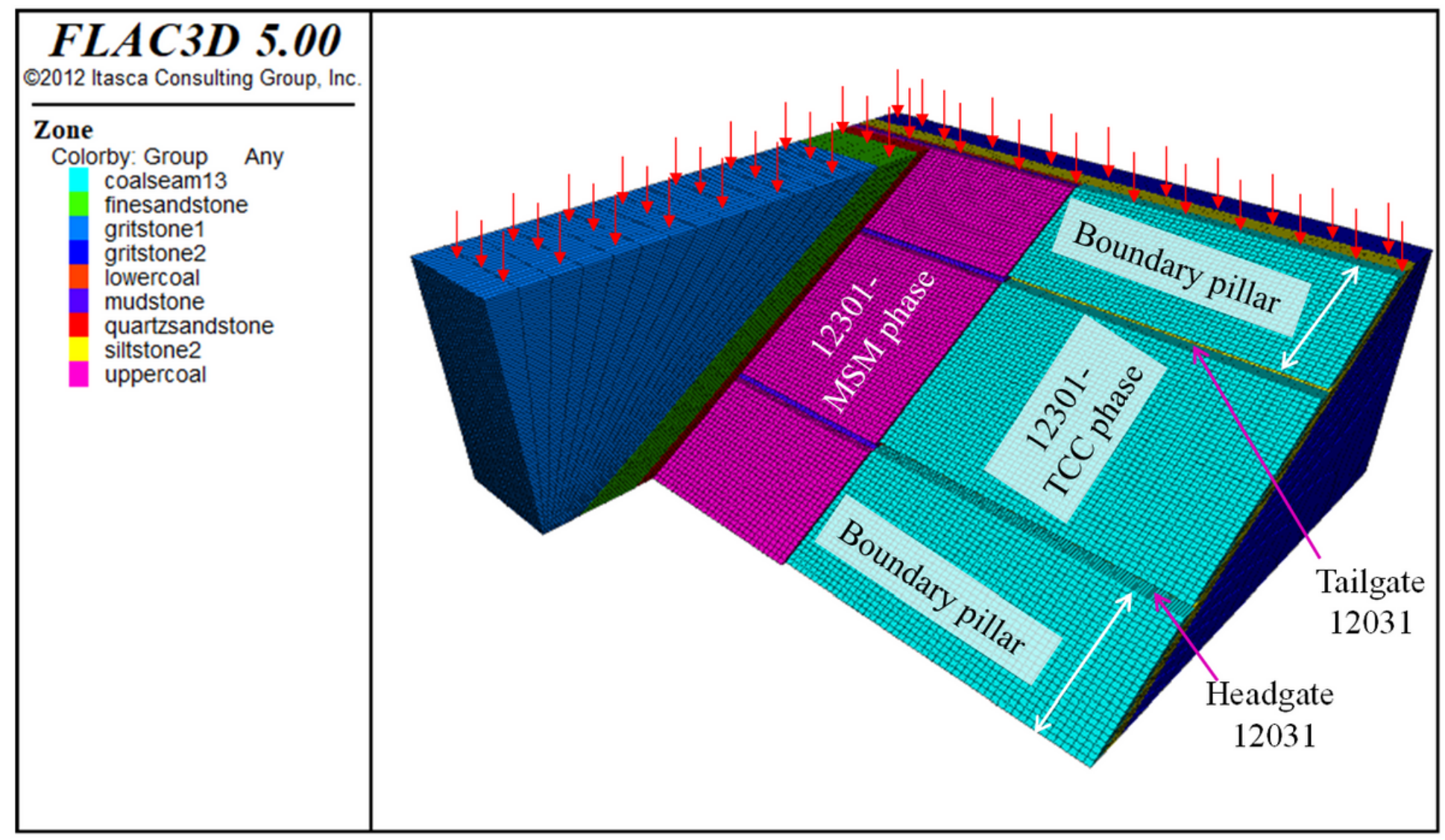

Figure 6

The structure of the numerical simulation model 


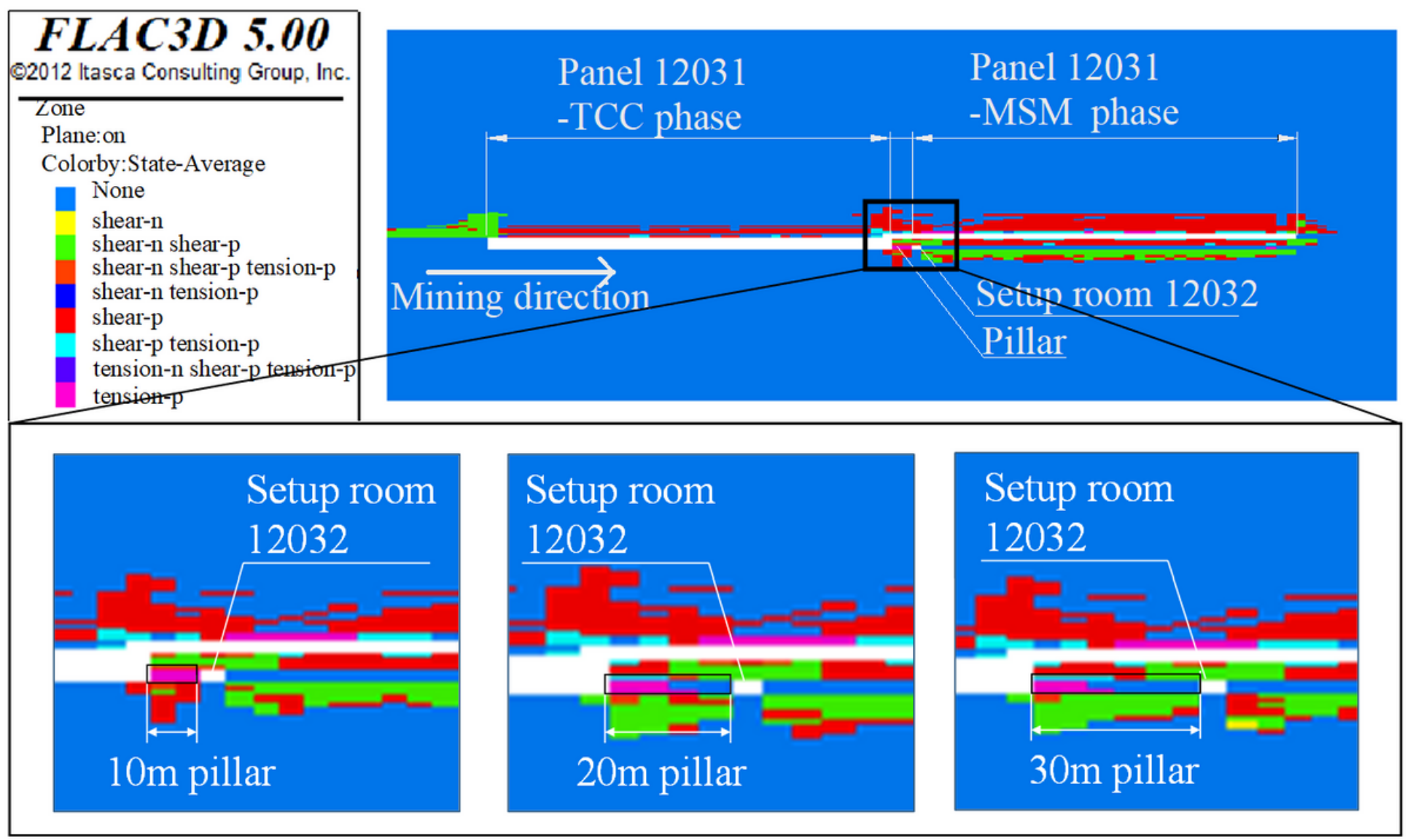

Figure 7

Simulation results of the plastic zone in different positions of the setup room of Panel 12032

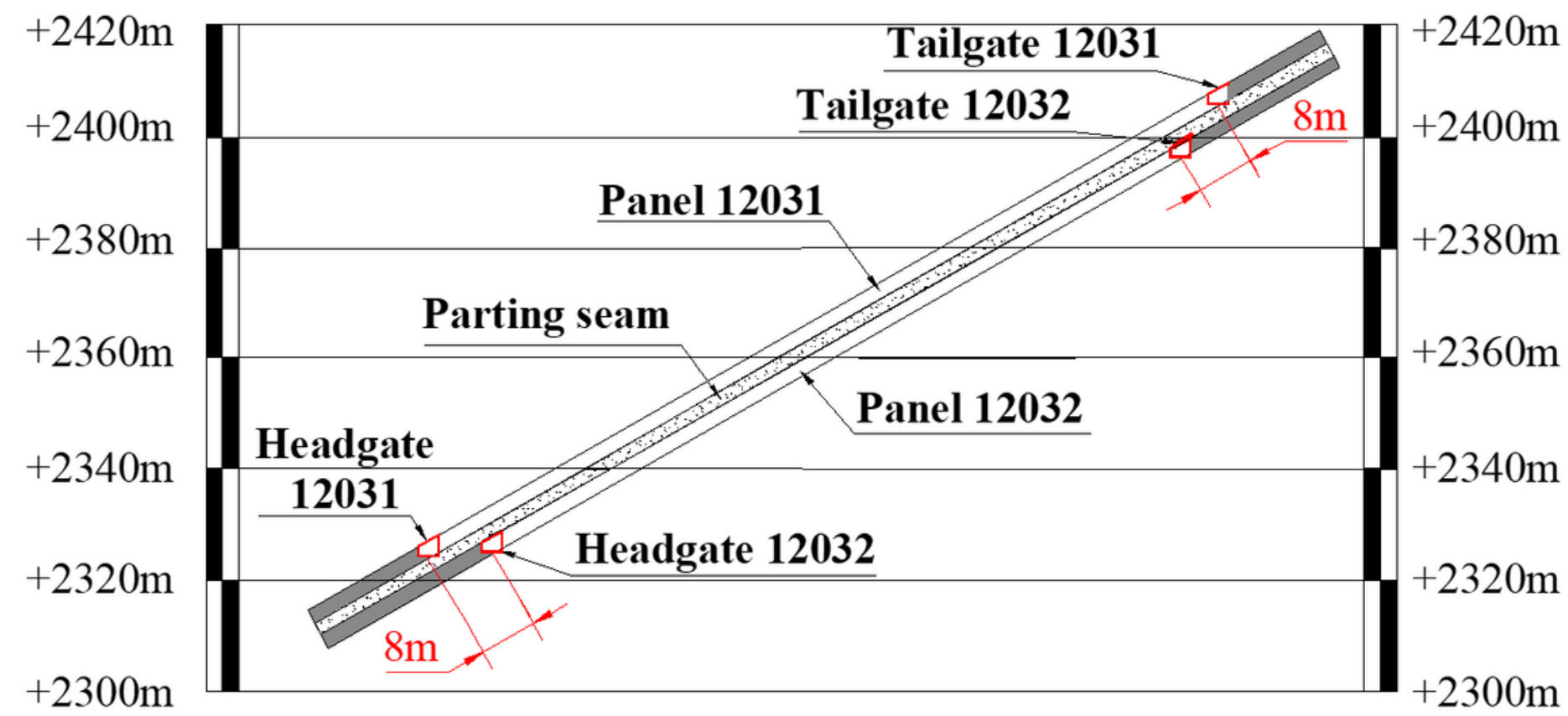

Figure 8 
Gate roads positions of Panel 12031 and 12032

Page 17/17 